\title{
EMISSIONS OF GREENHOUSE GASES FROM THE LIVESTOCK SECTOR
}

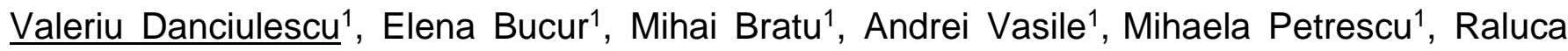
Diodiu $^{1}$, Gheorghita Tanase ${ }^{1}$

${ }^{1}$ National Research and Development Institute for Industrial Ecology - ECOIND, 71-73 Drumul Podu Dambovitei Street, sector 6, zip 060652, Bucharest, Romania

\begin{abstract}
In the livestock sector, the livestock activity involves also an air pollution with greenhouse gases, the main pollutants being methane, carbon dioxide and nitrogen protoxide. Depending on the farming system, the animal breed, the food supplied to the animals, and the manure management, various concentrations of gases with greenhouse effect may appear in the gaseous emissions. Emissions of gaseous pollutants from buildings where the animals are kept can pollute the atmosphere and can also affect the health of the farm workers. The natural ventilation of the stables has a major influence on the difficulty of determining the pollutant concentrations in the gaseous emissions, due to the inhomogeneity of the gas flow and the large variations in the pollutant concentrations at different points that are caused by the speed of the air movement through the venting holes and pollutant dispersion inside the building. This study presents the results obtained in a series of measurements of the levels of greenhouse gases at a dairy farm stable with natural ventilation. The equipment used for measurement was a portable gas chromatograph, Varian CP 4900. During the measurements, all the animals have been in the stable (they have not been taken to the pasture during that time).
\end{abstract}

Keywords: emissions, environment, greenhouse gases, livestock.

\section{Introduction}

The livestock sector through livestock management is a potential source of emissions that affects the health of the farm staff, of the animals and of the communities in the region surrounding the farm [1]. Although the number of animals can regionally decrease, the fast population growth as well as the increasing consumption of milk and meat globally, will certainly lead to an increase in gaseous emissions from the agricultural sector. Therefore, environmental problems associated with $\mathrm{CO}_{2}, \mathrm{CH}_{4}$ and $\mathrm{N}_{2} \mathrm{O}$ arising from this sector will persist, these greenhouse gases further affecting the global climate. The enteric fermentation and the manure management represent $30-45 \%$ of the total anthropogenic emissions of $\mathrm{CH}_{4}$ and $75-85 \%$ of $\mathrm{CH}_{4}$ emissions from agriculture. The livestock activities contribute up to $70 \%$ of global anthropogenic $\mathrm{N}_{2} \mathrm{O}$ emissions and represent $70-85 \%$ of the emissions from agriculture [2]. We have to take into consideration the fact that $\mathrm{CH}_{4}$ and $\mathrm{N}_{2} \mathrm{O}$ are greenhouse gases with global warming potential of 23 and 296 times, respectively, higher than that of the $\mathrm{CO}_{2}[3]$.

Reducing the emissions from the livestock sector depends on an understanding of the mechanisms, emission rates and other influencing factors such as livestock management systems, types of buildings and weather factors [4]. Naturally ventilated buildings are commonly used in cattle breeding sector because they are resistant to drafts and temperature changes and it is not necessary an additional heating of the indoor spaces. The rate of air exchange in the 
buildings depends on the meteorological parameters of the region such as the wind speed, the temperature and the topography of the region.

A database containing measurements of the levels of pollutants emitted can be used to improve the methods of estimating the emissions from the livestock sector and to develop methods to reduce these emissions [5].

The research presents the results of a case study regarding the evaluation of the emissions of greenhouse gases generated by the agriculture; thus, we monitored the concentrations of $\mathrm{CO}_{2}$, $\mathrm{CH}_{4}$ and $\mathrm{N}_{2} \mathrm{O}$ from a dairy barn provided with natural ventilation.

\section{Experimental}

The measurements were performed in a dairy barn that has an exhaust system for the liquid manure and natural ventilation of the building through ventilation windows mounted on the side walls under the eaves and also in the upper part of the roof. Occasionally, the doors of the side walls can be used to increase the ventilation. The floor has a raised platform with cow paddocks and a lower platform for collecting the manure that is mechanically scraped off by the scraper twice a day and stored outside the building, about $50 \mathrm{~m}$ away [6, 7]. The building dimensions are $90 \mathrm{~m}$ long and $25 \mathrm{~m}$ wide, wall height of $2.9 \mathrm{~m}$, and the maximum height of the roof is $7.9 \mathrm{~m}$.

During the measurement period, the stable was populated with 130 cows, with an estimated average body weight of $550 \mathrm{~kg}$ and the daily milk production was 29 liters/cow.

The concentrations of $\mathrm{CO}_{2}, \mathrm{~N}_{2} \mathrm{O} \mathrm{CH} 4$ in the air inside the barn were measured with a portable analyzer GC Varian CP 4900. The meteorological parameters were measured using a weather station mounted on the test van.

The measuring points were located at a height of $1.6 \mathrm{~m}$ in the 4 corners of the room (P1-P4) and 2 points located in the middle of the long sides of the building (P5 and P6), fig. 1. In the courtyard there were placed two measuring points (P7 and P8).

The measurements were performed during the warm period, in June 2016, when all the cows were kept inside the barn without being taken to grazing. The measurements were performed for one day and the meteorological parameters were characteristic to a warm day without rain.

Gas concentrations were recorded discontinuously, one sampling point at a time, for each of the 6 points inside and the 2 points outside.

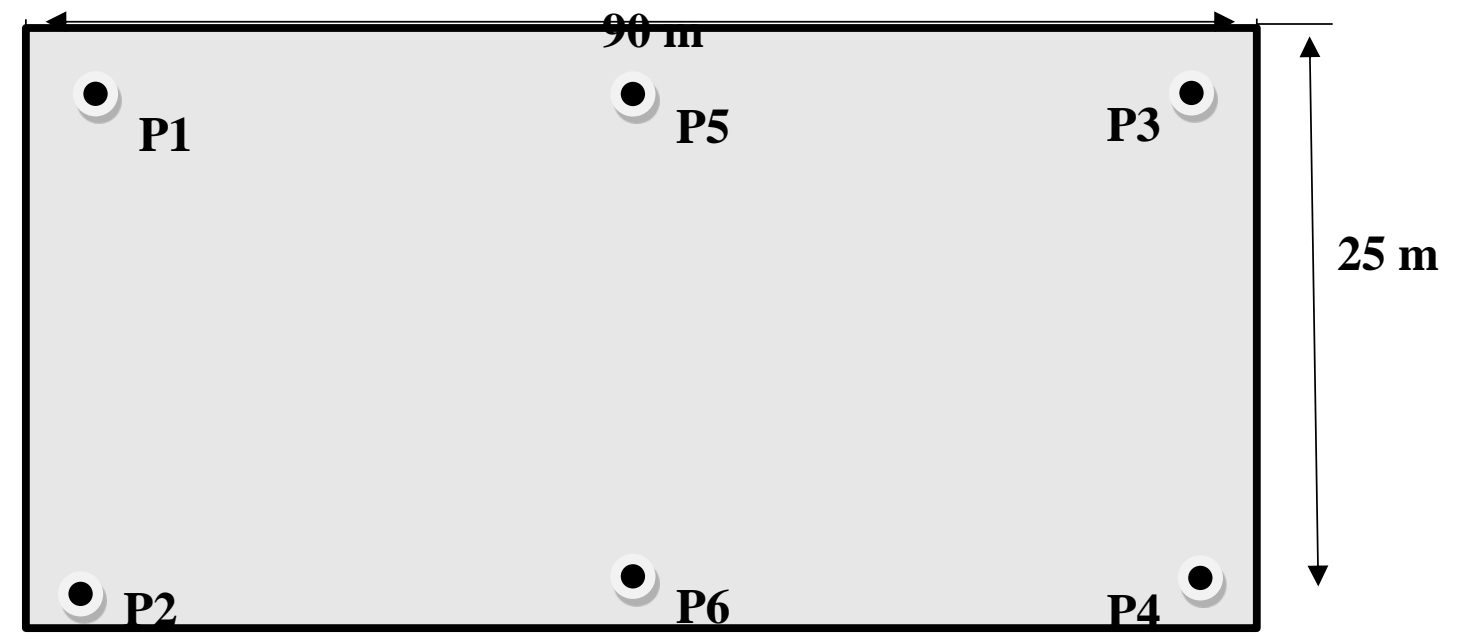

Fig. 1. Schematic of the barn showing the location of the measurement points (P1 - P6) 


\section{Results and Discussion}

The weather conditions around the buildings with animals (barns) are considered an extremely important factor concerning the pollutants emissions from naturally ventilated buildings. It has been observed that the speed of the wind has a direct influence on the ventilation and on the pollutant emission rate.

In terms of meteorological parameters, the period of time during which the measurements were performed was characterized by average temperatures of 27C, barometric pressure 1009 mbar and relative humidity of $29 \%$. The wind speed was $1.3 \mathrm{~m} / \mathrm{s}$, a value which can not significantly influence the ventilation in the building.

The average concentrations for $\mathrm{CO}_{2}, \mathrm{~N}_{2} \mathrm{O}$ and $\mathrm{CH}_{4}$ from the measurements inside and outside the dairy barn are presented in the Table 1. Analyzing the results, one observes much higher concentrations inside the barn as compared with the outdoor air for the $\mathrm{CO}_{2}$ and $\mathrm{CH}_{4}$, these pollutants being specific to the cattle breathing and digestion process. Another emission source of $\mathrm{CH}_{4}$ and $\mathrm{N}_{2} \mathrm{O}$ inside the barn is the fermentation process of the residues of feed and manure not removed from the barn.

Tabel 1. Mean concentrations of gases measured inside and outside the dairy barn.

\begin{tabular}{|c|c|c|c|}
\hline Measuring point & $\begin{array}{l}\mathrm{CO}_{2}, \\
\mathrm{ppm}\end{array}$ & $\begin{array}{l}\mathrm{CH}_{4}, \\
\mathrm{ppm}\end{array}$ & $\begin{array}{l}\mathrm{N}_{2} \mathrm{O} \\
\text { ppm }\end{array}$ \\
\hline \multicolumn{4}{|c|}{ Inside the barn } \\
\hline P1 & 1221 & 37 & 0.31 \\
\hline $\mathrm{P} 2$ & 1277 & 39 & 0.33 \\
\hline P3 & 1301 & 41 & 0.31 \\
\hline P4 & 1240 & 45 & 0.35 \\
\hline P5 & 1190 & 36 & 0.28 \\
\hline P6 & 1104 & 35 & 0.29 \\
\hline \multicolumn{4}{|c|}{ Outside the barn } \\
\hline P7 & 420 & 2.1 & 38 \\
\hline P8 & 395 & 1.9 & 37 \\
\hline
\end{tabular}

For the $\mathrm{N}_{2} \mathrm{O}$, the concentrations in the outdoor air are higher than those measured indoors - this pollutant is not specific to the animal breathing. Its presence in higher concentrations indicate a potential emission source outside; $\mathrm{N}_{2} \mathrm{O}$ most likely occurs in the spaces designated for the storage of manure, being easily dispersed in the surrounding air. The hypothesis of the existence of different emission sources, one common to $\mathrm{CH}_{4}$ and $\mathrm{CO}_{2}$ and the other mainly for $\mathrm{CH}_{4}$ and $\mathrm{N}_{2} \mathrm{O}$ is supported by Pearson correlation coefficient values (Table 2).

Table 2. Pearson correlation analysis results

\begin{tabular}{|c|c|c|c|c|}
\hline \multicolumn{2}{|c|}{} & $\mathrm{CO}_{2}$ & $\mathrm{CH}_{4}$ & $\mathrm{~N}_{2} \mathrm{O}$ \\
\hline \multirow{2}{*}{$\mathrm{CO}_{2}$} & Pearson Correlation & 1 & .643 & .572 \\
\cline { 2 - 5 } & Sig. (2-tailed) & & .168 & .235 \\
\hline \multirow{2}{*}{$\mathrm{CH}_{4}$} & Pearson Correlation & .643 & 1 & $.866^{*}$ \\
\cline { 2 - 5 } & Sig. (2-tailed) & .168 & & .026 \\
\hline \multirow{2}{*}{$\mathrm{N}_{2} \mathrm{O}$} & Pearson Correlation & .572 & $.866^{*}$ & 1 \\
\cline { 2 - 5 } & Sig. (2-tailed) & .235 & .026 & \\
\hline
\end{tabular}

*. Correlation is significant at the 0.05 level (2-tailed). 
Thus, one can observe a very good direct correlation $(r=0.866)$ between $\mathrm{CH}_{4}$ and $\mathrm{N}_{2} \mathrm{O}$ and a good correlation $\left(r=0.643\right.$ ) between $\mathrm{CH}_{4}$ and $\mathrm{CO}_{2}$, suggesting the existence of common emission sources for these pairs of pollutants. The weaker correlation between $\mathrm{CO}_{2}$ and $\mathrm{N}_{2} \mathrm{O}(r=0.572)$ may be due to emission from different sources but located in the same area.

Additional information on the pollutant concentrations over the entire barn has been obtained by analyzing the distribution of the isoconcentration curves for the three pollutants monitored (Fig. 2-4)

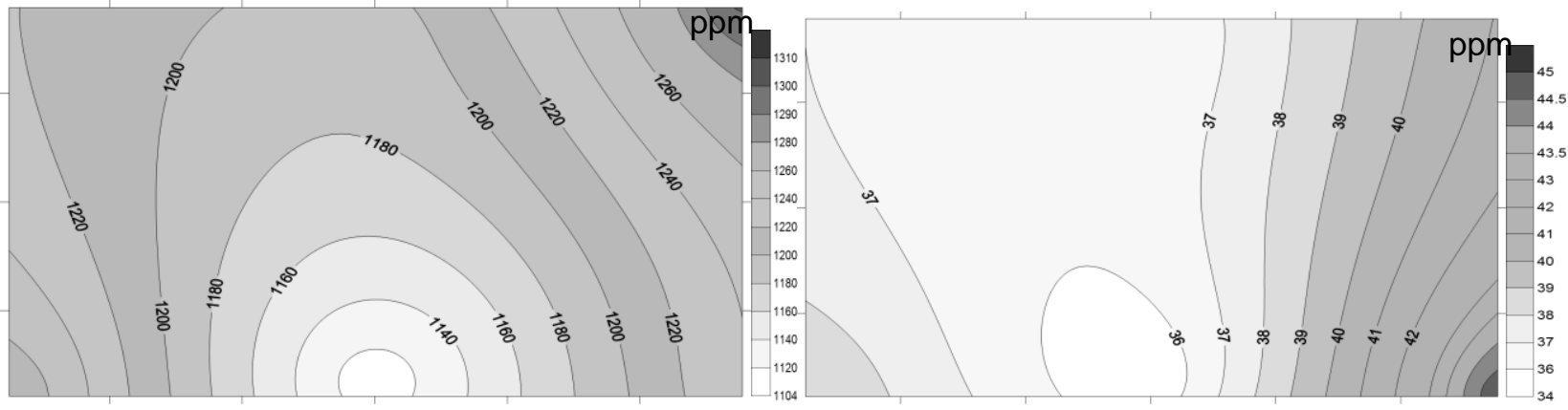

Fig. 1 - The distribution of the iso-concentrations of $\mathrm{CO}_{2}(\mathrm{ppm})$
Fig. 2 - The distribution of the iso-concentrations of $\mathrm{CH}_{4}(\mathrm{ppm})$

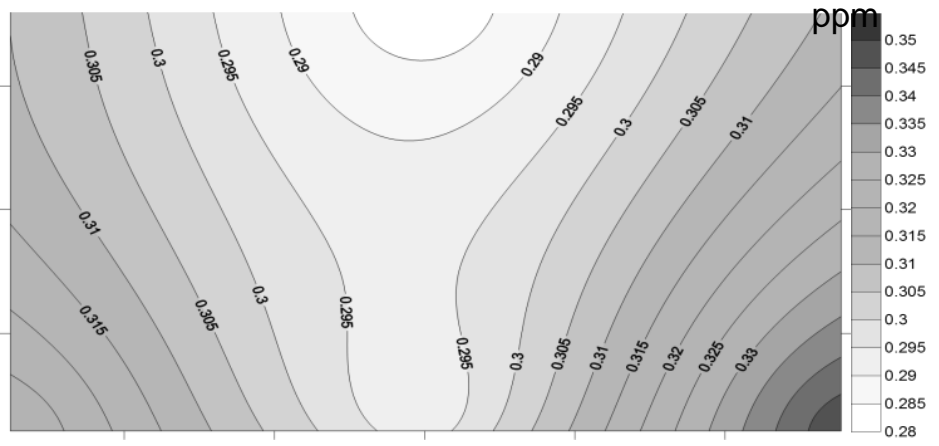

Fig. 3 - The distribution of the iso-concentrations of $\mathrm{N}_{2} \mathrm{O}(\mathrm{ppm})$

Differences can be observed between the concentrations measured in points from inside the barn. Thus, in points located in the middle of the building the concentrations are lower; in this place the ventilation is better than in the corners where greater amounts of pollutants can accumulate.

\section{Conclusions}

The concentrations of the three gases with greenhouse effect, $\mathrm{CO}_{2}, \mathrm{CH}_{4}$ and $\mathrm{N}_{2} \mathrm{O}$ are influenced by the process of digestion, cattle breathing and how the manure is managed. Farming activities can contribute up to $85 \%$ of anthropogenic emissions of greenhouse gases resulted from the agricultural sector.

In this study, the concentrations of $\mathrm{CO}_{2}, \mathrm{CH}_{4}$ and $\mathrm{N}_{2} \mathrm{O}$ were measured during the warm period in a barn with cows, with frequent removal of manure in liquid form. The relatively high concentrations of $\mathrm{CO}_{2}$ and $\mathrm{CH}_{4}$ are specific areas of cattle raising, and they did not vary much over time and space, being influenced by the dispersion of pollutants inside. The low concentrations of $\mathrm{N}_{2} \mathrm{O}$ suggest that the dairy barns are not a major source of $\mathrm{N}_{2} \mathrm{O}$. The $\mathrm{N}_{2} \mathrm{O}$ emissions are specific to the manure storage spaces.

The hypothesis of the existence of different emission sources, one common to $\mathrm{CH}_{4}$ and $\mathrm{CO}_{2}$ and the other mainly for $\mathrm{CH}_{4}$ and $\mathrm{N}_{2} \mathrm{O}$ is supported by Pearson correlation coefficient values. 
Short-term measurements at several points increase the representativeness of the gas concentrations inside a cattle barn.

The results obtained from the measurements of carbon dioxide, methane and nitrous oxide, make it possible to determine the influence of the food fed to the cattle on the level of emissions of greenhouse gases from livestock sector.

\section{Acknowledgements}

The authors are grateful for the financial support of project PN 16250111 (Contract no. $38 \mathrm{~N} / 2016)$

\section{References}

[1]. Y. Zhang, A. Tanaka, J.A. Dosman, A. Senthilselvan, E.M. Barber, S.P. Kirychuk, L.E. Holfeld, T.S. Hurst, Acute respiratory responses of human subjects to air quality in a swine building, Journal of Agricultural Engineering Research, 70 (4) (1998), pp. 367-373

[2]. FAO - Food and Agriculture Organization. Livestock's long shadow

[3]. IPPC 2006 -Third assessment report climate change. The scientific basis, Guidelines for National Greenhouse Gas Inventories, Emissions from Livestock and Manure Management

[4]. T.G.M. Demmers, V.R. Phillips, L.S. Short, L.R. Burgess, R.P. Hoxey, C.M. Wathes, Validation of ventilation rate measurement methods and the ammonia emission from naturally ventilated dairy and beef buildings in the United Kingdom, Journal of Agricultural Engineering Research, 79 (1) (2001), pp. 107-116 [5]. R.W. Sneath, F. Beline, M.A. Hilhorst, P. Peu, Monitoring GHG from manure stores on organic and conventional dairy farms, Agriculture, Ecosystems \& Environment, 112 (2-3) (2006), pp. 122-128

[6]. N.M. Ngwabie, K.-H. Jeppsson, S. Nimmermark, C. Swensson, G. Gustafsson, Multi-location measurements of greenhouse gases and emission rates of methane and ammonia from a naturallyventilated barn for dairy cows, Biosystems Engineering,Volume 103, Issue 1, May 2009, Pages 68-77 [7]. Bjarne Bjerg, Guoqiang Zhang, Jørgen Madsen, Hans B. Rom, Methane emission from naturally ventilated livestock buildings can be determined from gas concentration measurements, Environmental Monitoring and Assessment, October 2012, Volume 184, Issue 10, pp 5989-6000 